\title{
Tuned Optical Front-End MMIC Amplifiers for a Coherent Optical Receiver
}

\section{Petersen, Anders Kongstad; Jagd, A M}

\section{Published in:}

Proceedings of the 22nd European Microwave Conference

Link to article, DOI:

10.1109/EUMA.1992.335846

Publication date:

1992

Document Version

Publisher's PDF, also known as Version of record

Link back to DTU Orbit

Citation $(A P A)$ :

Petersen, A. K., \& Jagd, A. M. (1992). Tuned Optical Front-End MMIC Amplifiers for a Coherent Optical Receiver. In Proceedings of the 22nd European Microwave Conference (Vol. Volume 2, pp. 1065-1070). IEEE. https://doi.org/10.1109/EUMA.1992.335846

\section{General rights}

Copyright and moral rights for the publications made accessible in the public portal are retained by the authors and/or other copyright owners and it is a condition of accessing publications that users recognise and abide by the legal requirements associated with these rights.

- Users may download and print one copy of any publication from the public portal for the purpose of private study or research.

- You may not further distribute the material or use it for any profit-making activity or commercial gain

- You may freely distribute the URL identifying the publication in the public portal 

RECEIVER

\author{
A K Petersen* , A M Jagd*
}

\begin{abstract}
$\underline{\text { ABSTRACT }}$
Two low noise tuned optical front-end GaAs MESFET MMIC amplifiers for a coherent optical CPFSK (Continuous Phase Frequency Shift Keying) receiver are presented. The receiver operates at $2.5 \mathrm{Gbit} / \mathrm{s}$ at an IF of approx. $9 \mathrm{GHz}$. The front-ends are based on full-custom designed MMICs and a commercially available GaInAs/InP pin photo diode.

The procedure for measuring the transimpedance and the equivalent input noise current density is outlined in this paper and demonstrated using one of the MMICs.

The MMICs were fabricated using the Plessey F20 process by GEC-Marconi through the ESPRIT programme EUROCHIP, and they both occupy $2 \mathrm{~mm}^{2}$.
\end{abstract}

\title{
INTRODUCTION
}

During the last few years the development of Gbit/s coherent optical communication systems has been remarkable. Hybrid circuits are widely used in receivers for such systems. However, in order for coherent systems to have high reliability, low power consumption and eventually to be of low cost, a high degree of integration should be used. Hence, it is interesting to investigate how the progressing maturity of GaAs MESFET MMIC technology can be exploited in coherent receivers. The main purpose of our research is therefore to use conventional MESFET technology for coherent receivers. The demands for e.g. front-ends in a coherent receiver are very stringent because the bandwidth is approx. twice the bitrate, A.K.Petersen and A.M.Jagd [1]. Wavelengths in long-haul communication systems are in the range $1300-1550 \mathrm{~nm}$, so a photo diode based on Ga-As-In-P compounds is necessary. In this case a commercially available $\mathrm{GaAsIn} / \mathrm{hnP}$ photo diode with a $25 \mathrm{GHz}$ bandwidth is used, Wake et al. [2].

\section{CIRCUIT TOPOLOGY}

Design of the front-ends is based on transformer tuning, G.Jacobsen et al. [3]. The use of transformer tuning decreases the thermal receiver noise considerably and so reduces the local oscillator power needed to obtain shot noise limited detection. Figure 1 illustrates the principles of transformer tuning where $\mathrm{C}_{1}, \mathrm{~L}_{1}, \mathrm{C}_{2}$ and $\mathrm{L}_{2}$ form two resonant circuits, where the capacitors are parasitics from photo diode and FET, respectively.Transformer tuning is used as matching between diode and input FET as well as inter stage matching. Transformer tuning can be realized either using a T-equivalent or a $\Pi$-equivalent circuit as shown in figure 1.

* Center for Broadband Telecommunications

Technical University of Denmark

Building 348

2800 Lyngby

Denmark 

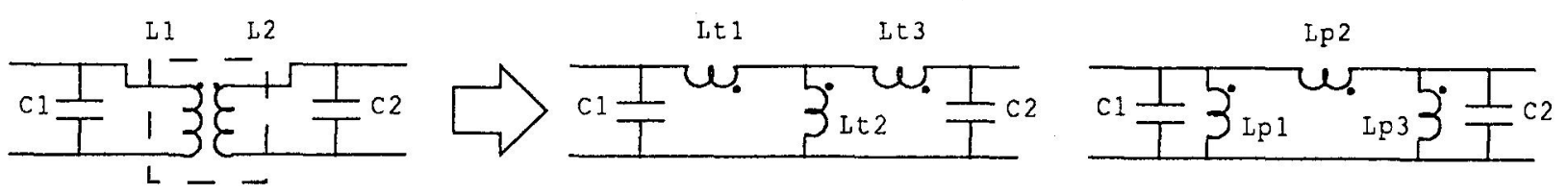

Figure $1 \mathrm{~T}$ - and $\Pi$-realization of transformer tuning

A schematic of the two front-ends is shown in figure 2. The difference between the two designs is the realization of the inter stage matching, where T-equivalent and $\Pi$-equivalent inter stage matching are used. $\mathrm{L}_{\mathrm{b} 2}-\mathrm{L}_{\mathrm{b} 4}$ form the tuning between the photo diode and the MMICs. $\mathrm{L}_{\mathrm{b} 2}-\mathrm{L}_{\mathrm{b} 4}$ are realized as bond wires. $\mathrm{C}_{7}-\mathrm{C}_{10}$ are dicaps forming $\mathrm{AC}$ shorts. $\mathrm{C}_{3}-\mathrm{C}_{6}, \mathrm{C}_{11}, \mathrm{C}_{13}$ and $\mathrm{C}_{15}-\mathrm{C}_{17}$ are on-chip $\mathrm{AC}$ by-pass capacitors, $\mathrm{L}_{1}-\mathrm{L}_{5}$ are inter stage and output stage tuning elements.

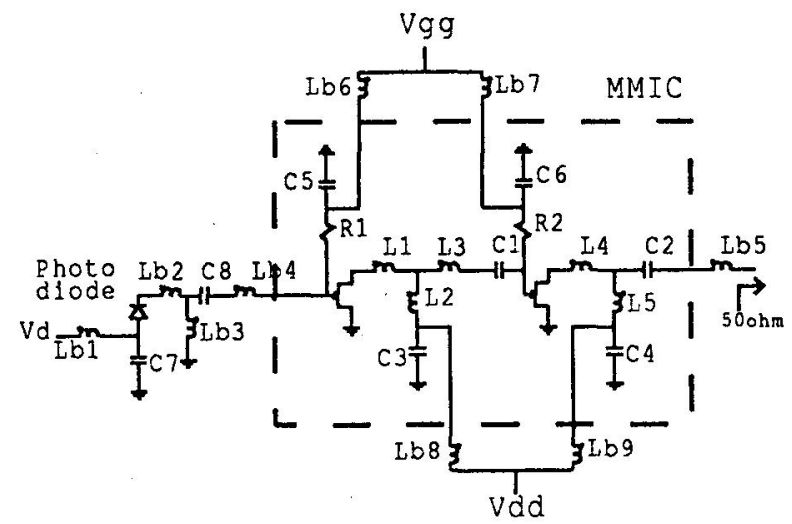

a)

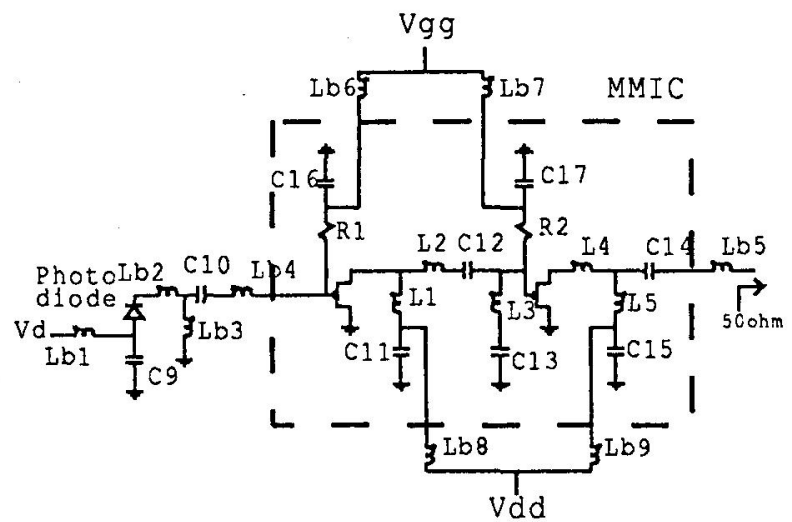

b)

Figure 2 Front-end schematics with a) $\mathrm{T}$-type inter stage tuning and b) $\Pi$-type inter stage tuning.

\section{SIMULATIONS}

The design approach for the front-ends is divided into the following steps:

- Diode characterizations and modelling

- $\quad$ MMIC design and simulation of transimpedance and equivalent input noise current density

- Wafer probing of MMICs and comparison of measured and simulated S-parameters

- Simulation of transimpedance based on measured S-parameters

- Mounting of MMICs with photo diodes and measuring of transimpedance and equivalent input noise current density

Using the diode model it has been possible to simulate the transimpedance and the equivalent input noise current density, M. Høgdal [3]. These simulations are shown in figure 6 and 7 as solid curves. As shown in figure 6 the expected transimpedance for the front-end with T-equivalent inter stage tuning is $42.5 \mathrm{~dB} \Omega \pm 1.5 \mathrm{~dB} \Omega$ in the frequency range $6 \mathrm{GHz}-12 \mathrm{GHz}$, the expected input noise current density is $12-15 \mathrm{pA} / \sqrt{\mathrm{Hz}}$.

Figure 7 shows the expected transimpedance for the front-end with П-equivalent inter stage tuning. This front-end has an expected transimpedance of $42 \mathrm{~dB} \Omega \pm 1.5 \mathrm{~dB} \Omega$ in the frequency. range 6.5 $\mathrm{GHz}-11.5 \mathrm{GHz}$, and the expected input noise current density is $12-16 \mathrm{pA} / \sqrt{\mathrm{Hz}}$. 


\section{MEASUREMENTS}

The photo diode is mounted on a separate substrate offering the possibility to characterize the solitary photo diode mounted on the substrate. The MMICs were designed on the basis of measured diode performance. To perform a preliminary comparison between measurements and simulations, the Sparameters of the front-end MMICs were measured in a $50 \Omega$ system using on-chip probing and a HP8510B network analyzer. A comparison between measured and calculated $S_{21}$ for the two MMICs are shown in figure 4 and 5 , respectively. Good agreement is observed for the front-end with $\Pi$ tuning (fig.5), although the measured $S_{21}$ is shifted slightly towards lower frequencies. Excellent agreement between measured and calculated $S_{21}$ and for the front-end with T-tuning (fig.4).

After the preliminary test of the MMICs, they were mounted with the photo diodes. The measurement procedure for measuring transimpedance and equivalent input noise current density is outlined below.

a)

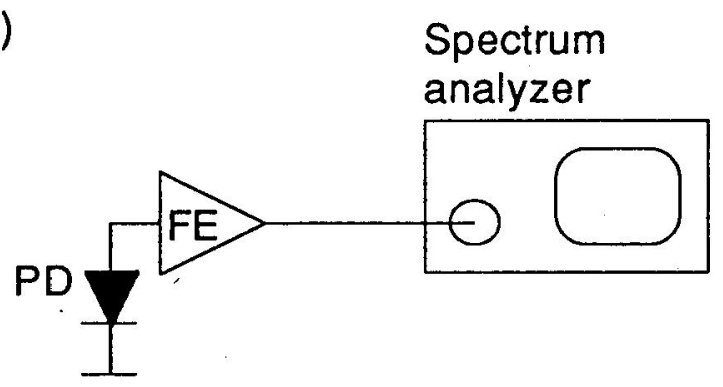

c)

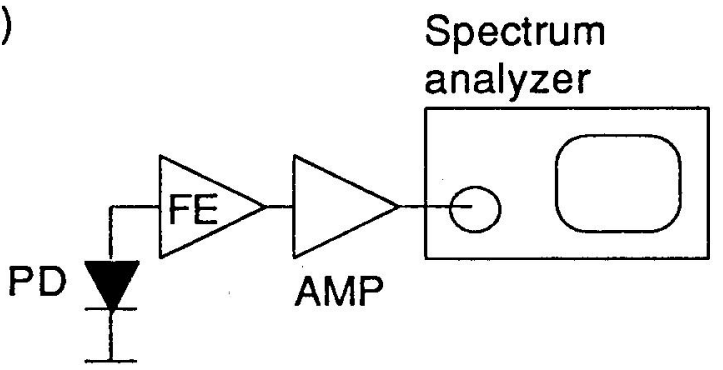

b)

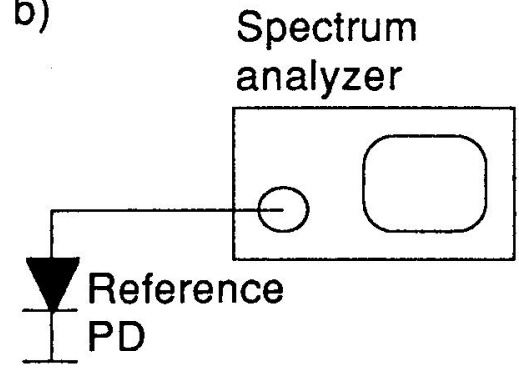

Figure 3 Measurement set-up for transimpedance and noise measurements

To obtain the transimpedance of the front-end, two power spectra are measured. The first power spectrum is measured with the set-up shown in figure $3 \mathrm{a}$ ). The photo diode is illuminated by two semiconductor DFB lasers using a fibre coupler. One laser (LO) is oscillating at a fixed frequency and the other $(S)$ is swept with a saw-tooth generator. The optical signals are mixed in the photo diode and a microwave signal from $0-18 \mathrm{GHz}$ is generated at the output of the photo diode. Along with the power spectrum, $\mathrm{P}_{1}(\mathrm{f})$, the photo diode currents, $\mathrm{I}_{\mathrm{LO}}$ and $\mathrm{I}_{\mathrm{S} 1}$, are measured with the swept laser turned off and the fixed laser turned off, respectively. The same measurements are performed with the set-up on figure $3 \mathrm{~b}$ ), here $\mathrm{P}_{2}(\mathrm{f}), \mathrm{I}_{\mathrm{LO} 2}$ and $\mathrm{I}_{\mathrm{S} 2}$ are measured for a reference photo diode. This calibration measurement is used to determine the absolute transimpedance level (the transimpedance of the photo diode in a $50 \Omega$ system is $34 \mathrm{~dB} \Omega$ ). Using these two measurements the transimpedance, $\mathrm{Z}_{\mathrm{t}}$, is calculated as

$$
Z_{\mathrm{l}}(\mathrm{f})=20 \log \left(\mathrm{Z}_{0}\right)+\mathrm{P}_{1}(\mathrm{f})-\mathrm{P}_{2}^{*}+10 \log \left(\frac{\mathrm{I}_{\mathrm{LO} 2} \cdot \mathrm{I}_{\mathrm{S} 2}}{\mathrm{I}_{\mathrm{LO} 1} \cdot \mathrm{I}_{\mathrm{S} 1}}\right)[\mathrm{dB} \Omega]
$$

where $\mathrm{P}_{2}^{*}$ is the low frequency level for $\mathrm{P}_{2}(\mathrm{f})$.

To measure the equivalent input noise current density, three additional power spectra measurements are made. A low noise amplifier is first inserted between the front-end and the spectrum analyzer to decrease the noise figure seen from the output of the front-end ( figure $3 \mathrm{c}$ )). The gain of the inserted 
amplifier is easily found by measuring the third spectrum, $\mathrm{P}_{3}(\mathrm{f})$ and the photo currents $\mathrm{I}_{\mathrm{LO}}$ and $\mathrm{I}_{\mathrm{S} 3}$. The gain is given by

$$
G=P_{3}(f)-P_{1}(f)+10 \log \left(\frac{I_{L O 1} \cdot I_{S 1}}{I_{L O 3} \cdot I_{S 3}}\right)[d B]
$$

Finally two spectra measurements are performed where the photo diode is not illuminated. When the photo diode is not illuminated the total noise spectrum, $\mathrm{P}_{4}(\mathrm{f})$, from the front-end, amplifier and spectrum analyzer is measured. The last power spectrum is measured with the bias for the front-end turned off. During this measurement the noise spectrum, $P_{5}(f)$, is measured. The difference in noise power gives the noise power generated in the front-end. The measured noise spectrum at the output of the front-end for these two measurements is calculated as

$$
\begin{aligned}
& \mathrm{N}_{1}=\mathrm{P}_{4}(\mathrm{f})-10 \log \left(\mathrm{B}_{\mathrm{n}}\right)+2.5 \mathrm{~dB}-\mathrm{G}\left[\frac{\mathrm{dBm}}{\mathrm{Hz}}\right] \\
& \mathrm{N}_{2}=\mathrm{P}_{5}(\mathrm{f})-10 \log \left(\mathrm{B}_{\mathrm{n}}\right)+2.5 \mathrm{~dB}-\mathrm{G}\left[\frac{\mathrm{dBm}}{\mathrm{Hz}}\right]
\end{aligned}
$$

where $B_{n}$ is the noise bandwidth used in the spectrum analyzer and, $G$, the gain of the amplifier. The $2.5 \mathrm{~dB}$ comes from the fact that narrow band white noise is measured.

Finally the equivalent input noise current density, $\mathrm{I}_{\text {neq }}$, can be calculated as

$$
I_{\text {neq }}=\frac{\sqrt{\left(\mathrm{N}_{1}\left[\frac{\mathrm{W}}{\mathrm{Hz}}\right]-\mathrm{N}_{2}\left[\frac{\mathrm{W}}{\mathrm{Hz}}\right] \sqrt{\mathrm{Z}_{0}}\right.}}{\mathrm{Z}_{\mathrm{t}}}
$$

where $\mathrm{Z}_{0}=50 \Omega$.

The result of the measurement of transimpedance and equivalent input noise current density is shown in figure 6 for the front-end with T-tuning. Good agreement between measurements and simulations are obtained over some of the frequency range, but an unexpected discrepancy is observed in the frequency range $11-14 \mathrm{GHz}$. We believe this discrepancy is due to improper design of the bias circuit for the MMIC. Another cause could be the bond wire tuning between the photo diode and the MMIC, but this is not very likely since the low frequency cut off at $5 \mathrm{GHz}$ is very sensitive to this tuning circuit and very good agreement is obtained in this frequency range.

The measured transimpedance and equivalent input noise current density of the front-end with $\Pi$ tuning were not available at the paper deadline. To predict the front-end transimpedance of the received MMIC, a simulation has been performed where the measured S-parameters for the MMIC in a $50 \Omega$ system and the modelled photo diode were used. The predicted transimpedance was compared to the original simulations ( see figure 7 ). We expect to present measured transimpedance and noise current density for the $\Pi$-tuned front-end at the conference, to verify the good agreement shown in the figure.

\section{CONCLUSION}

Two different types of transformer tuned pin-diode front-ends were designed using a commercially available MESFET GaAs foundry service and a commercially available pin photo diode. One 
amplifier uses $\mathrm{T}$-equivalent inter stage tuning, and the other one uses $\Pi$-equivalent inter stage tuning. A transimpedance of approximately $42 \mathrm{~dB} \Omega$ and an equivalent input noise current density in the range $10-16 \mathrm{pA} / \sqrt{\mathrm{Hz}}$ for both front-ends was expected. Excellent agreement between simulated and measured S-parameters was obtained for the MMICs.

The bandwidth of the T-tuned front-end was smaller than expected, but in the pass-band good agreement was obtained both between transimpedance and equivalent input noise current density. In the pass-band the transimpedance was between $37-44 \mathrm{~dB} \Omega$ and the noise current density $10-17$ $\mathrm{pA} / \sqrt{\mathrm{Hz}}$.

\section{REFERENCES}

[1] A.K.Petersen and A.M.Jagd, "A 6 - $12 \mathrm{GHz}$ tuned optical front-end MMIC amplifier for a coherent optical receiver", International symposium on MMICs in communication systems, 1992, London

[2] D.Wake et al., "Planar-junction, Top-illuminated GaInAs/InP pin photodiode with bandwidth of $25 \mathrm{GHz}$ ", Electronics Letters, Vol. 25, No. 15, 1989, pp. 967-968

[3] G.Jacobsen, J.X.Kan and I.Garrett, "Tuned Front-End Design for Heterodyne Optical Receivers", IEEE J. Lightwave Technology, vol. 7, 1989, pp. 105-114

[4] M.Høgdal, Submitted for publication in Journal of Lightwave Technology, 1992

\section{ACKNOWLEDGEMENT}

The authors would like to acknowledge Frank Ebskamp, Center for Broadband Telecommunications, for his support and encouragement during the design and measurement of the front-ends. 


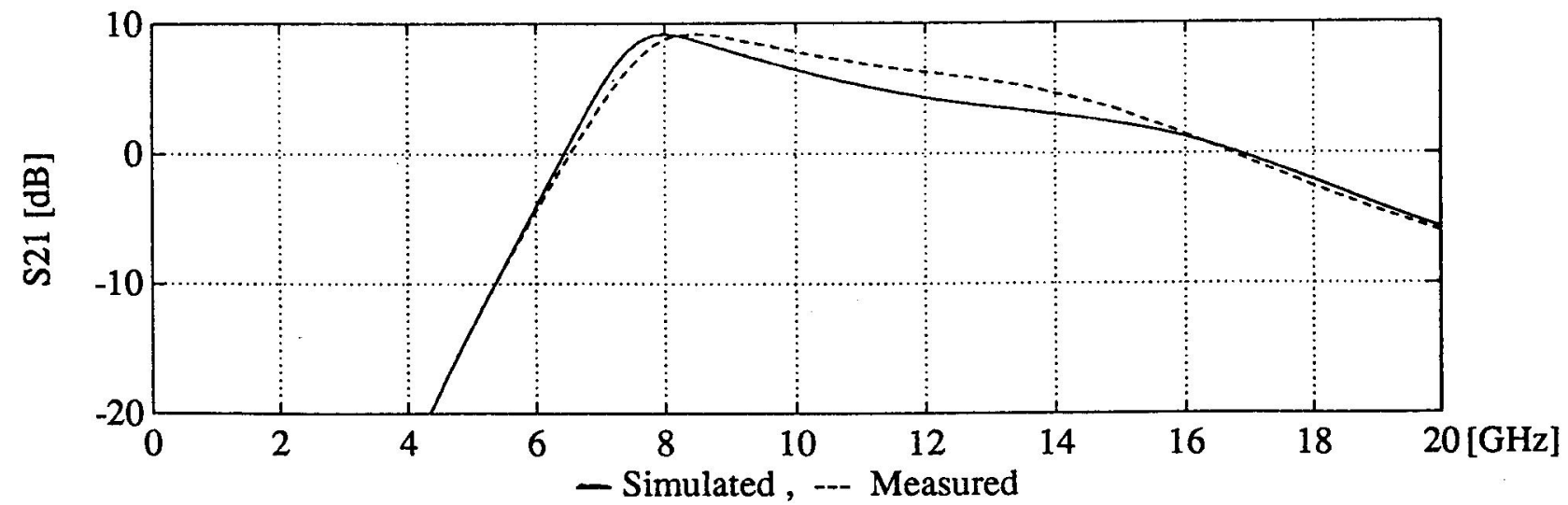

Figure 4 Measured and simulated $S_{21}$ for MMIC with T-tuning.

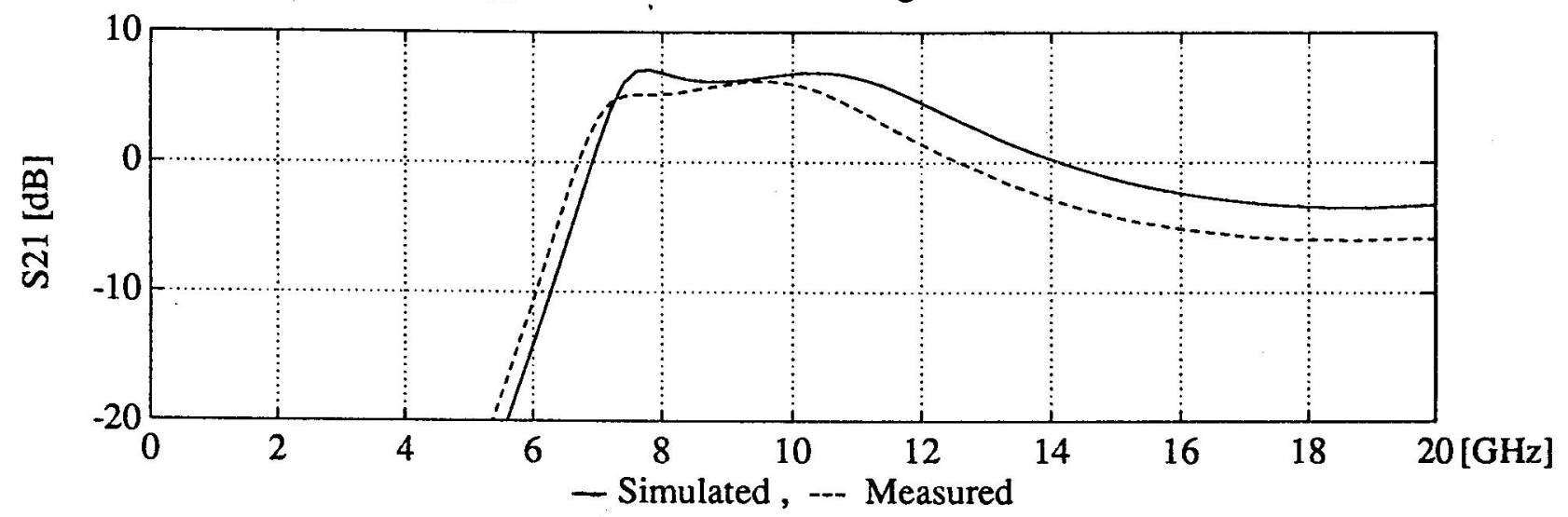

Figure 5 Measured and simulated $S_{21}$ for MMIC with $\Pi$-tuning.

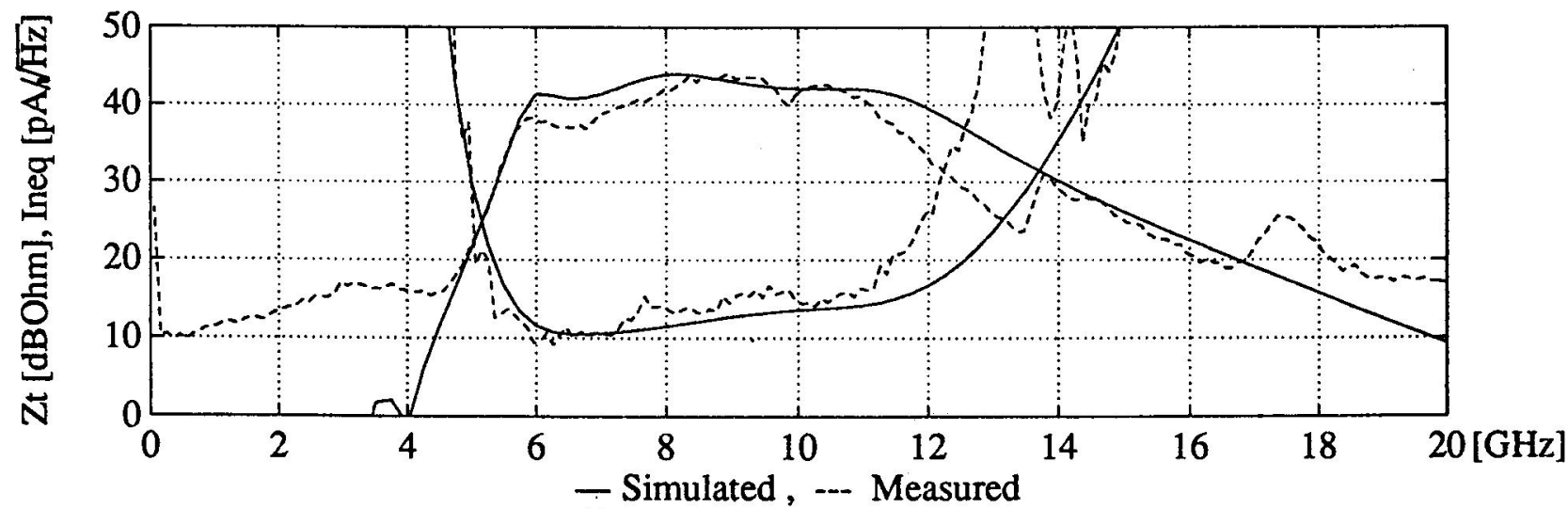

Figure 6 Transimpedance and equivalent input noise current density for front-end with T-tuning.

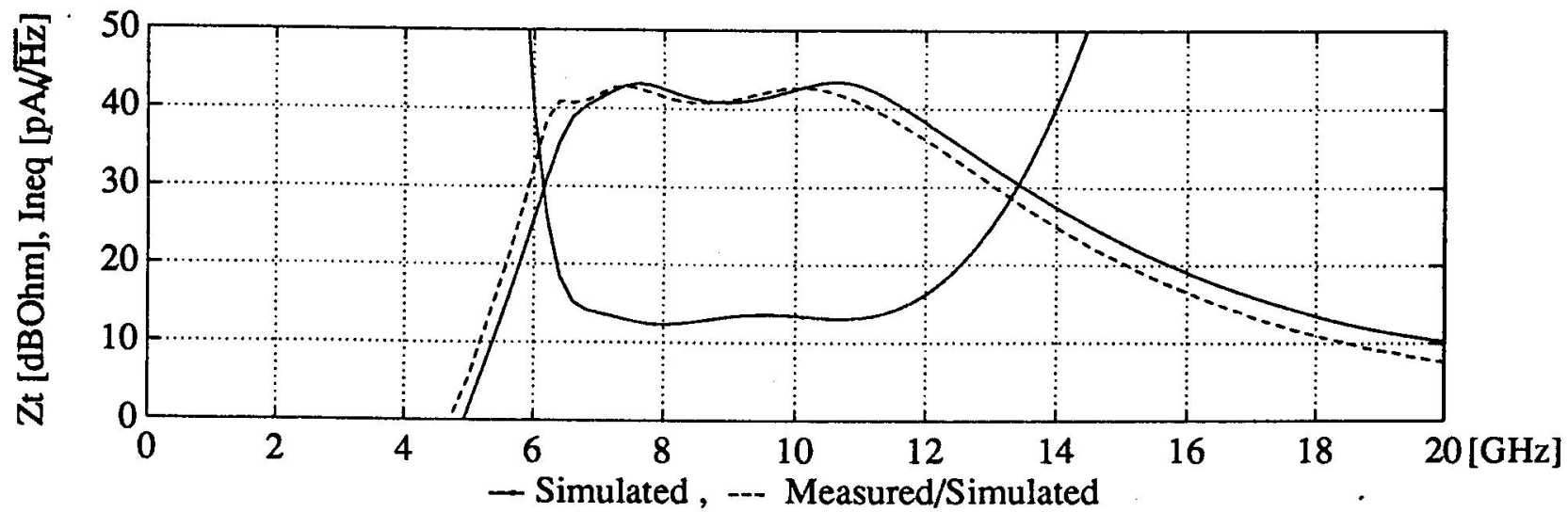

Figure 7 Transimpedance and equivalent input noise current density for front-end with $\Pi$-tuning. 